\title{
Measuring the quality of palliative care and supportive oncology: principles and practice
}

\author{
Sydney M. Dy, MD, MSc
}

Department of Health Policy and Management and the Harry J. Duffey Family Pain and Palliative Care Program, Hopkins Kimmel Cancer Center, Johns Hopkins, Baltimore, Maryland

Oncology quality measurement programs should include measures in key domains of palliative care and supportive oncology. This article describes an approach to quality measurement in these areas including the key steps of defining the quality measurement goal; identifying stakeholders and audiences; defining the population and setting (including potential characteristics of interest, such as specific conditions or disparities); and choosing the domain, target, and steps in the process of care, such as assessment and treatment. Other key steps include choosing or adapting measures that have been evaluated in other settings or are in widespread use; identifying data sources or collection needs; and considering issues of scientific acceptability, such as evidence to support process-outcome relationships. Other quality measurement considerations include the challenges of measurement, particularly in important domains such as communication and spiritual care, variation in patient preferences, or inconsistent documentation. In addition, potential unintended consequences, such as measurement burden and overemphasis of checklist care, may reduce patient-centeredness and attention to important patient concerns not addressed by quality measures.

$\mathrm{P}$ alliative care quality indicators should be part of oncology performance assessment initiatives. Palliative care programs should also include initiatives to address the overall quality of palliative care issues, such as pain management, in the settings where the programs are located. ${ }^{1}$ Measuring quality facilitates justifying palliative care initiatives and documenting their impact, targeting quality improvement efforts, monitoring care for deficiencies, and evaluating providers (Table 1). However, measurement in this field is often not straightforward. Potential challenges include defining the population to measure and data sources, collection and analysis, as well as choosing among many potentially relevant issues and quality measures.

This article describes an approach to quality measurement in palliative care, beginning with a description of key frameworks to guide the measurement approach. The article also reviews key steps in designing a quality measurement program, which include defining the quality problem

Manuscript received March 30, 2013; accepted July 18, 2013. Correspondence Sydney M. Dy, MD, MSc, Associate Professor, Rm 609, 624 N Broadway, Baltimore, MD 21205 (sdy@jhsph.edu).

Disclosures The author has completed and submitted the ICMJE Form for Disclosure of Potential Conflicts of Interest and none were reported.

J Support Oncol 2013;11:160-164 @ 2013 Frontline Medical Communications DOI: 10.12788/j.suponc.0017 and population to measure and choosing domains and specific measures. Finally, the article addresses other key considerations, such as considering unintended consequences and using data for quality improvement.

\section{Frameworks for evaluating quality}

The Donabedian framework of structure (stable elements of the health care system), process (what health care services are provided), and outcome (end results for the patient and family) can be applied to relevant domains to guide evaluation design (Table 2). ${ }^{2-8}$ Key structural elements may include characteristics of programs (eg, palliative clinic availability), providers (eg, multidisciplinary members of the palliative care team), and tools (eg, do-not-resuscitate policies). Processes may include technical aspects of care, such as appropriate prescribing and interpersonal aspects of care (eg, coordination among providers). Outcomes may include patient quality of life or symptoms, perceptions of care, or caregiver outcomes such as burden. Outcomes may also be categorized as overuse (eg, use of chemotherapy at the end of life compared to national benchmarks), underuse (eg, lower rates of hospice care or use of antinausea drugs), or appropriateness of care (eg, accurately documenting patients' preferences for care). 
TABLE 1 Potential goals for measuring quality in palliative care and supportive oncology

\begin{tabular}{ll}
\multicolumn{1}{c}{ Purpose } & \multicolumn{1}{c}{ Example measurement fargets } \\
\hline Justify need for a palliative care program & Extended hospitalizations, intensive care unit stays near the end of life \\
Demonstrate where improvements are needed & $\begin{array}{l}\text { Pain scores } \\
\text { Documentation of end-of-life discussions }\end{array}$ \\
Evaluate impact of new programs or quality improvement & Patient/family perceptions of care \\
Monitor care for deficiencies, worsening care & $\begin{array}{l}\text { Patient safety reporting on pain management issues } \\
\text { Help patients, families, providers make informed choices }\end{array}$ \\
\hline
\end{tabular}

TABLE 2 Structure, process, and outcome in palliative care and supportive oncology

\begin{tabular}{|c|c|}
\hline Domain & Examples \\
\hline Structure ${ }^{1}$ & Leadership support, culture \\
\hline Programs & $\begin{array}{l}\text { Outpatient clinic } \\
\text { 24-hour availability }\end{array}$ \\
\hline Providers & $\begin{array}{l}\text { Board-certified physicians } \\
\text { Availability of other interdisciplinary team members } \\
\text { Training of unit staff }\end{array}$ \\
\hline Tools & $\begin{array}{l}\text { Comfort care order sets } \\
\text { Hospital policy on goals of care discussion }\end{array}$ \\
\hline \multicolumn{2}{|l|}{ Process } \\
\hline Technical excellence ${ }^{3,4}$ & $\begin{array}{l}\text { Appropriate and well-delivered treatments, coordination } \\
\text { Underuse - Was treatment given for severe pain? } \\
\text { Overuse - Did the patient receive chemotherapy in the last } 2 \text { weeks of life? }\end{array}$ \\
\hline Interpersonal excellence & Communication, empathy 5,6 \\
\hline \multicolumn{2}{|l|}{ Outcome } \\
\hline Patient/family-centered & Symptom management, patient perceptions of care \\
\hline Utilization & Hospitalizations, hospice use at the end of life $e^{3,7,8}$ \\
\hline
\end{tabular}

\section{Developing a quality measurement plan}

The first step in developing a plan is to define the purpose, such as planning for palliative care services, monitoring for problems, or evaluating a suspected quality deficit. Framing the purpose should account for the intended audience for data to be collected and key stakeholders (eg, different providers, disciplines, and management). A prioritization process involving discussion with stakeholders and review of existing data can help determine which issues are most important and of most interest to involved providers. ${ }^{7}$ Other criteria include identifying issues that likely need improvement and can be influenced by providers within the setting.

\section{Defining the population and settings}

Choosing the population (denominator) for measurement should be based on the goal and domains of care chosen (eg, measurement of the rate of use of hospice care is usually applied retrospectively to the population who have died and were treated by a given provider). Measuring care across settings is challenging as most current indicators are setting-specific. Therefore, choosing the key setting (eg, the need for communication about end-of-life issues in high-risk patients in the intensive care unit) is also an important initial step. When defining the denominator, one should consider the need to evaluate for disparities in quality of care to ensure that specific vulnerable subgroups at potentially higher risk of poorer quality are adequately sampled.

Defining the population prospectively or in real time is often not straightforward in palliative care initiatives. For example, the inclusion of too broad a population within a setting (eg, all patients seen in a cancer center) may dilute the purpose of measurement (eg, only a small percentage have severe pain or need pain medications). However, identifying a target population with advanced disease or limited life expectancy is also often challenging, even with sophisticated information systems. Key data points for defining a palliative care population, such as stage of 
disease, performance status, prognosis, goals, or line of chemotherapy, are often neither routinely documented nor available in electronic systems. Solutions include targeting groups of patients easily identifiable with a high likelihood of limited prognosis and palliative care needs (eg, non-surgical lung or pancreatic cancer); linking to other sources of information (eg, cancer registry data); or screening for risk factors where data is available, such as recent or multiple hospitalizations or high pain scores.

\section{Choosing domains, targets and steps}

Using professional consensus from 5 major US palliative care organizations, the National Consensus Project (NCP) defines broad clinical domains and specific targets for palliative care and can be translated to specialist-level palliative care delivered in different settings and to integrating palliative care into usual practice. ${ }^{1}$ These include the following domains:

- Physical aspects of care, including targets of symptoms such as pain and function;

- Psychological and psychiatric aspects of care, including symptoms such as depression and delirium as well as grief and bereavement;

- Social aspects of care, such as caregiving and coping;

- Spiritual, religious, and existential aspects of care;

- Cultural aspects of care, such as cultural competency and use of a translator;

- Care at the end of life; and

- Ethical and legal aspects of care, such as advance directives.

Other domains and targets may be relevant for supportive oncology and cancer care settings, such as delivery of care (communication and decision-making) and the use of treatments (chemotherapy, radiation therapy, or other invasive procedures $)^{9}$ where the intent is to palliate but there are significant risks and burden (eg, pleural and biliary drains). Additional domains for supportive oncology measures address the complications of cancer as well as the side effects and complications of chemotherapy. ${ }^{10}$

Due to lack of guidelines or scientific evidence, some of these domains are more challenging to measure than others and measures may not yet have been developed. Other challenges include lack of agreement on what is quality and subjectivity or variation in patient preferences or approaches to care. Measurement issues include lacking or inconsistent documentation in the medical record and lack of inclusion in usual data sources, such as standard electronic health record fields. Reliably identifying whether a medication was given is more feasible to measure than whether communication occurred or the quality of the specified communication. For example, spirituality and cultural issues, although important, are little-developed areas, although standards now include more detail. ${ }^{1}$ Existing measures such as the presence of a spiritual assessment or whether a translator was used may also not be consistently documented.

Within these domains and targets, specific steps in the process of care include screening, assessment/diagnosis, treatment (eg, for symptoms) or implementation (eg, for communication), and follow-up. For the example of pain, in the Cancer Quality-ASSIST (Assessing Symptoms Side Effects and Indicators of Supportive Treatment) supportive oncology set, indicators could evaluate what percentage of the time cancer patients were screened for pain or what percentage of patients who screened for moderate-severe pain had key elements of a pain assessment. Other steps include what percentage of $\mathrm{pa}^{-}$ tients with severe pain had treatment or documentation of why treatment was not offered, and what percentage had some follow-up after a change in treatment. ${ }^{10}$ The choice of steps may depend on the extent of process implementation in a setting (eg, if pain screening is already well-established in a cancer center, measurement may focus on more advanced processes, such as treatment). Simply focusing on a single step may be insufficient to improve quality. For example, research has found that increased pain screening alone does not lead to improved pain outcomes. ${ }^{11}$

Cross-cutting processes are also important in palliative care, such as care coordination, continuity and transitions (eg, improving communication and care consistent with goals across providers or settings). ${ }^{12}$ However, these types of process indicators are more challenging to develop and test. With fragmented care systems, they are more effectively addressed at the level of structure, such as a standard location in the medical record for documenting goals of care or including information on advance directives in a standard discharge summary template. ${ }^{13}$ They can also be addressed as outcomes using patient or family surveys (see below).

\section{Choosing process indicators within domains, data sources, and methods}

Ideally, quality measurement initiatives should use or adapt existing indicators that have been tested for reliability and validity, are currently used in other settings for relevant measurement projects, and are feasible in available data sources. Quality measurement in palliative care can involve utilization data for issues such as hospitalizations at the end of life; medical record review for issues such as pain management; or survey data, such as after-death surveys sent to families of hospice patients. Newer sources of data include the electronic medical record or other information system reports, including patient-reported outcome data (such as distress or depression screens) included in the medical record. Observational data (eg, observing or audio 
TABLE 3 Selected medical record review quality indicator sets relevant to palliative care and supportive oncology

\begin{tabular}{|c|c|c|c|}
\hline Set & Description & Relevant domains & Example indicator(s) \\
\hline \multicolumn{4}{|l|}{ Oncology } \\
\hline $\begin{array}{l}\mathrm{ASCO} \\
\mathrm{QOPI}^{3}\end{array}$ & $\begin{array}{l}\text { Outpatient oncology (palliative } \\
\text { care part of larger } \\
\text { measurement set); in } \\
\text { widespread use; selected } \\
\text { indicators NQF-endorsed }\end{array}$ & $\begin{array}{l}\text { Pain, dyspnea, communication/ } \\
\text { decision-making, hospice/ } \\
\text { palliative care referral; also } \\
\text { includes utilization indicators } \\
\text { (hospice use, location of } \\
\text { death, chemotherapy last } 2 \\
\text { weeks of life) }\end{array}$ & $\begin{array}{l}\text { Pain assessed on either of the last } 2 \\
\text { visits before death; plan of care } \\
\text { for moderate/severe pain } \\
\text { documented on either of the last } \\
2 \text { visits before death }\end{array}$ \\
\hline \multicolumn{4}{|l|}{ Supportive oncology } \\
\hline Cancer Quality-ASSIST ${ }^{4,14}$ & $\begin{array}{l}\text { Outpatient and hospital; } \\
\text { benchmarking data } \\
\text { available; selected } \\
\text { indicators NQF-endorsed }\end{array}$ & $\begin{array}{l}\text { Pain, dyspnea, delirium, } \\
\text { insomnia, fatigue, nausea/ } \\
\text { vomiting, other side effects of } \\
\text { chemotherapy, appropriate } \\
\text { management of complications, } \\
\text { advance care planning }\end{array}$ & $\begin{array}{l}\text { If a patient with cancer undergoes } \\
\text { chemotherapy then prior to } \\
\text { chemotherapy, s/he should be } \\
\text { informed about the risks and } \\
\text { benefits of treatment, including } \\
\text { likely symptoms and side effects } \\
\text { and whether the treatment intent } \\
\text { is curative or palliative }\end{array}$ \\
\hline \multicolumn{4}{|l|}{ Geriatrics } \\
\hline $\begin{array}{l}\text { ACOVE } \\
\text { End of Life }{ }^{14,15}\end{array}$ & $\begin{array}{l}\text { Outpatient, hospital; } \\
\text { benchmarking data } \\
\text { available }\end{array}$ & $\begin{array}{l}\text { Pain, dyspnea, } \\
\text { nausea/vomiting, } \\
\text { communication/ } \\
\text { decision-making/ } \\
\text { care planning, psychosocial, } \\
\text { continuity, spiritual }\end{array}$ & $\begin{array}{l}\text { If a hospitalized vulnerable elder } \\
\text { requires mechanical ventilation } \\
\text { for longer than } 48 \text { hours, then } \\
\text { within } 48 \text { hours of the initiation } \\
\text { of mechanical ventilation, the } \\
\text { medical record should document } \\
\text { the goals of care and the } \\
\text { patient's preference for } \\
\text { mechanical ventilation or why } \\
\text { this information is unavailable }\end{array}$ \\
\hline \multicolumn{4}{|l|}{ Intensive care } \\
\hline $\begin{array}{l}\text { VHA Comfort and } \\
\text { Communication in the } \\
I^{C U^{16}}\end{array}$ & Intensive care & $\begin{array}{l}\text { Pain, communication/decision- } \\
\text { making, psychosocial, } \\
\text { spiritual }\end{array}$ & $\begin{array}{l}\text { Medical decision maker: Percentage of } \\
\text { patients with documentation of status } \\
\text { of identification of health care proxy } \\
\text { (or other appropriate surrogate) } \\
\text { (within } 24 \text { hours of ICU admission) }\end{array}$ \\
\hline
\end{tabular}

Abbreviations: ACOVE, Assessing Care of Vulnerable Elders; ASCO, American Society of Clinical Oncology; ASSIST, Assessing Symptoms Side Effects and Indicators of Supportive Treatment; ICU, Intensive Care Unit; NQF, National Quality Forum; QOPI, Quality Oncology Practice Initiative.

recording and documenting key elements of family meetings) are also potential sources. However, data collection is resource-intensive.

Whenever possible, initiatives should use or adapt measures that have already been evaluated for feasibility, reliability, and validity. Two key sources for indicators are the National Quality Forum (www.qualityforum.org) and the National Quality Measures Clearinghouse of the Agency for Healthcare Research and Quality (AHRQ; www.qualitymeasures.ahrq.gov). Several key quality indicator sets relevant to palliative care and supportive oncology in different populations and settings are listed in Table 3.,14-16

Specific quality indicators can be evaluated using 4 criteria. Importance is defined as choosing indicators that are based on evidence and related to key quality domains and outcomes. They should be high-priority issues within the program or organization and be linked to known or suspected quality problems. Scientific acceptability relates to the ability to produce consistent and believable results, including well-defined and precisely specified data elements as well as evidence that they can accurately identify clinically meaningful differences in quality. Specifications may include exclusions or (for outcome measures) risk adjustment specifications. For example, many palliative care indicators exclude patients who cannot self-report symptoms such as pain. Use and usability refer to indicators that are in current use and that generate information usable in quality activities, such as demonstrating performance gaps that can be addressed. Indicators may also have benchmarking data or data available from other programs or from exemplary programs that allow comparisons to determine where specific deficiencies exist. Finally, feasibility refers to the extent to which the data is available or can be readily obtained 
and includes the characteristics of low error rates and adequate sample size. ${ }^{7,17}$

\section{Discussion}

Palliative care and supportive oncology quality measures should be included in oncology performance assessment initiatives, and quality measurement is key to the success of palliative care programs. This article describes key steps and principles for palliative care and supportive oncology quality measurement, including setting a quality measurement goal; defining the stakeholders and audience; defining the population of interest; choosing domains, targets, data sources, and specific measures of interest; and considering the scientific strength and usability of the measures and any adaptations needed. Although many indicators are now available, quality measurement in this area is limited by the challenges of:

- Defining and targeting palliative-care populations;

- Assessment in vulnerable populations;

- Lack of consistent documentation of many aspects of care in medical records; and

- Measuring more subjective domains such as communication and spiritual care.

Recognizing the limitations and potential adverse effects of quality measurement is important in designing a program and choosing measures. Even a comprehensive set of quality measures can only account for a very small percentage of the health care provided and cannot accurately reflect the full spectrum of actions critical to quality care, such as answering patient questions, planning to prevent potential crises, or coordinating between providers. In addition, over-standardization or attempting to meet benchmarks that are set too high (eg, a goal of reaching $100 \%$ compliance) can have unintended consequences. For example, a measure of do-not-resuscitate conversations at hospital admission can cause unwarranted patient distress if communication is done poorly or at an inappropriate time. A screen of a severe pain score does not always require increasing medications - the pain may be temporary or a patient may have preferences for burdens and benefit of pain treatment that should be considered. Measurement of the percentage of $\mathrm{pa}-$ tients who die at home or who die in the location consistent with their preferences needs to acknowledge that home is not always the most appropriate place for death, especially with difficult-to-manage symptoms. Caregiver preferences and burden should also be considered.

Measurement programs must also be vigilant for "checkbox medicine”. Requiring too many checkboxes (eg, requiring assessment of all symptoms at every visit) without evidence to support the effectiveness of such an intervention can lead to spending time on meeting standards rather than on what mat- ters most to the patient and potentially overtreatment if providers feel obligated to address each symptom. The costs and burden of quality measurement must be weighed against potential benefits in designing a program and deciding which measures to keep and how frequently to measure. Finally, measurement is not an end in itself. Feedback to providers or administrators alone is relatively ineffective in changing care, and key identified deficiencies in care need to be addressed through quality improvement initiatives.

\section{References}

1. National Consensus Project for Quality Palliative Care. Clinical Practice Guidelines for Quality Palliative Care. Third Edition. http://www.nationalconsensusproject.org, 2013.

2. Donabedian A. The quality of care. How can it be assessed? JAMA. 1988;260(12):1743-1748.

3. Campion FX, Larson LR, Kadlubek PJ, Earle CC, Neuss MN. Advancing performance measurement in oncology: quality oncology practice initiative participation and quality outcomes. J Oncol Pract. 2011;7(3 Suppl):31s-5s.

4. Dy SM, Lorenz KA, O’Neill SM, et al. Cancer Quality-ASSIST supportive oncology quality indicator set: feasibility, reliability, and validity testing. Cancer. 2010;115(13):3267-3275.

5. Teno JM, Lima JC, Lyons KD. Cancer patient assessment and reports of excellence: reliability and validity of advanced cancer patient perceptions of the quality of care. J Clin Oncol. 2009;27(10):1621-1626.

6. Connor SR, Teno J, Spence C, Smith N. Family evaluation of hospice care: results from voluntary submission of data via website. J Pain Symptom Manage. 2005;30(1):9-17.

7. McGlynn EA, Asch SM. Developing a clinical performance measure. Am J Prev Med. 1998;14(3 Suppl):14-21.

8. Earle CC, Neville BA, Landrum MB, et al. Evaluating claimsbased indicators of the intensity of end-of-life cancer care. Int $J$ Qual Health Care. 2005;17(6):505-509.

9. Seow H, Snyder CF, Mularski RA, et al. A framework for assessing quality indicators for cancer care at the end of life. J Pain Symptom Manage. 2009;38(6):903-912.

10. Lorenz KA, Dy SM, Naeim A, et al. Quality measures for supportive cancer care: the cancer quality-ASSIST Project. $J$ Pain Symptom Manage. 2009;37(6):943-964.

11. Mularski RA, White-Chu F, Overbay D, Miller L, Asch SM, Ganzini L. Measuring pain as the 5th vital sign does not improve quality of pain management. J Gen Intern Med. 2006;21(6):607-612.

12. Teno JM, Gozalo PL, Bynum JP, et al. Change in end-of-life care for Medicare beneficiaries: site of death, place of care, and health care transitions in 2000, 2005, and 2009. JAMA. 2013;309(5):470-477.

13. American Medical Association. Care Transitions Performance Measurement Set. 2009. http://www.ama-assn.org/ama/pub/ physician-resources/physician-consortium-performanceimprovement.page. Accessed August 12, 2013.

14. Walling AM, Asch SM, Lorenz KA, et al. The quality of care provided to hospitalized patients at the end of life. Arch Intern Med. 2010;170(12):1057-1063.

15. Lorenz KA, Rosenfeld K, Wenger N. Quality indicators for palliative and end-of-life care in vulnerable elders. $J$ Am Geriatr Soc. 2007;55(Suppl 2):S318-S326.

16. Nelson JE, Mulkerin CM, Adams LL, Pronovost PJ. Improving comfort and communication in the ICU: a practical new tool for palliative care performance measurement and feedback. Qual Saf Health Care. 2006;15(4):264-271.

17. National Quality Forum, Measure Evaluation Criteria. Available from: http://www.qualityforum.org/docs/measure_evaluation_criteria. aspx. Accessed July 1, 2013. 